\title{
Giant Verrucous Haemangioma with Linear Features - A Rare Entity and Successful Treatment with Complete Excision and Grafting
}

\author{
Kanakapura Nanjundaswamy Shivaswamy, S Shanthakumar, K Rashmi, A L \\ Shyamprasad, T K Sumathy and M Y Suparna
}

M S Ramaiah Medical College, Bangalore-560054, Karnataka, India

Correspondence should be addressed to: Kanakapura Nanjundaswamy Shivaswamy; drkns75@gmail.com

Received date: 29 October 2014; Accepted date: 12 February 2015; Published date: 17 May 2016

Academic Editor: Seçil Soylu

Copyright (C) 2016. Kanakapura Nanjundaswamy Shivaswamy, S Shanthakumar, K Rashmi, A L Shyamprasad, T K Sumathy and M Y Suparna. Distributed under Creative Commons CC-BY 4.0

\begin{abstract}
Verrucous haemangioma is a rare vascular malformation which presents at birth or in childhood as an asymptomatic bluish-red soft papules, plaques, and nodules over legs, which become verrucous later in life. Recurrent bleeding and secondary infections are common. [1]There are only a few reports of linear forms of this condition. [4, 5, 6] Sudden increase in size following trauma along with bleeding and secondary infection are common in this condition [7]. We are reporting a giant verrucous hemangioma with linear features successfully treated with excision and grafting.
\end{abstract}

Keywords: Verrucous, hemangioma, linear, excision, grafting

\section{Introduction}

Verrucous hemangioma is a rare vascular malformation which presents at birth or in childhood as asymptomatic bluish-red soft papules, plaques, and nodules over legs, which become verrucous later in life. Recurrent bleeding and secondary infections are common. [1] Lesions may measure up to $8 \mathrm{~cm}$ in diameter. Linear verrucous haemangioma is even rarer with a few published reports. [4, 5, 6] Here we are presenting giant verrucous haemangioma with linear features successfully treated with excision and grafting.

\section{Case Report}

A 23 year old female patient presented to us with history of raised lesions over her right

Cite this Article as: Kanakapura Nanjundaswamy Shivaswamy, S Shanthakumar, K Rashmi, A L Shyamprasad, T K Sumathy and M Y Suparna (2016), "Giant Verrucous Haemangioma with Linear Features - A Rare Entity and Successful Treatment with Complete Excision and Grafting", JMED Research, Vol. 2016 (2016),

Article ID 952849, DOI: 10.5171/2016. 952849 
leg. On enquiry, these lesions were present since birth. Initially, started as pink patches and gradually progressed to become raised lesions. The lesions started to increase in the size and associated with pain since a year for which she came seeking for treatment. On examination, multiple skin coloured to hyperpigmented verrucous papules and plaques of varying sizes, arranged in a linear fashion noted over anteromedial and anterior aspect of middle $1 / 3^{\text {rd }}$ of right leg extending up to the dorsum and sole of foot. One of the verrucous plaques was measuring more than $10 \mathrm{~cm}$ along the long axis [Fig 1]. Histopathological examination from one of the representative specimen showed compact hyperkeratosis, acanthosis and numerous ectatic vascular channels filled with red blood cells in the upper and mid dermis extending up to lower dermis [Fig2, Fig 3, ]. With this, a diagnosis of verrucous haemangioma was arrived at... Magnetic resonance angiogram (MR angiogram) of the right leg was done to delineate the depth of involvement. Since, there were no musculoskeletal and deep vascular connections; a planned excision of lesions with subsequent skin grafting was done in multiple stages [Fig 4].

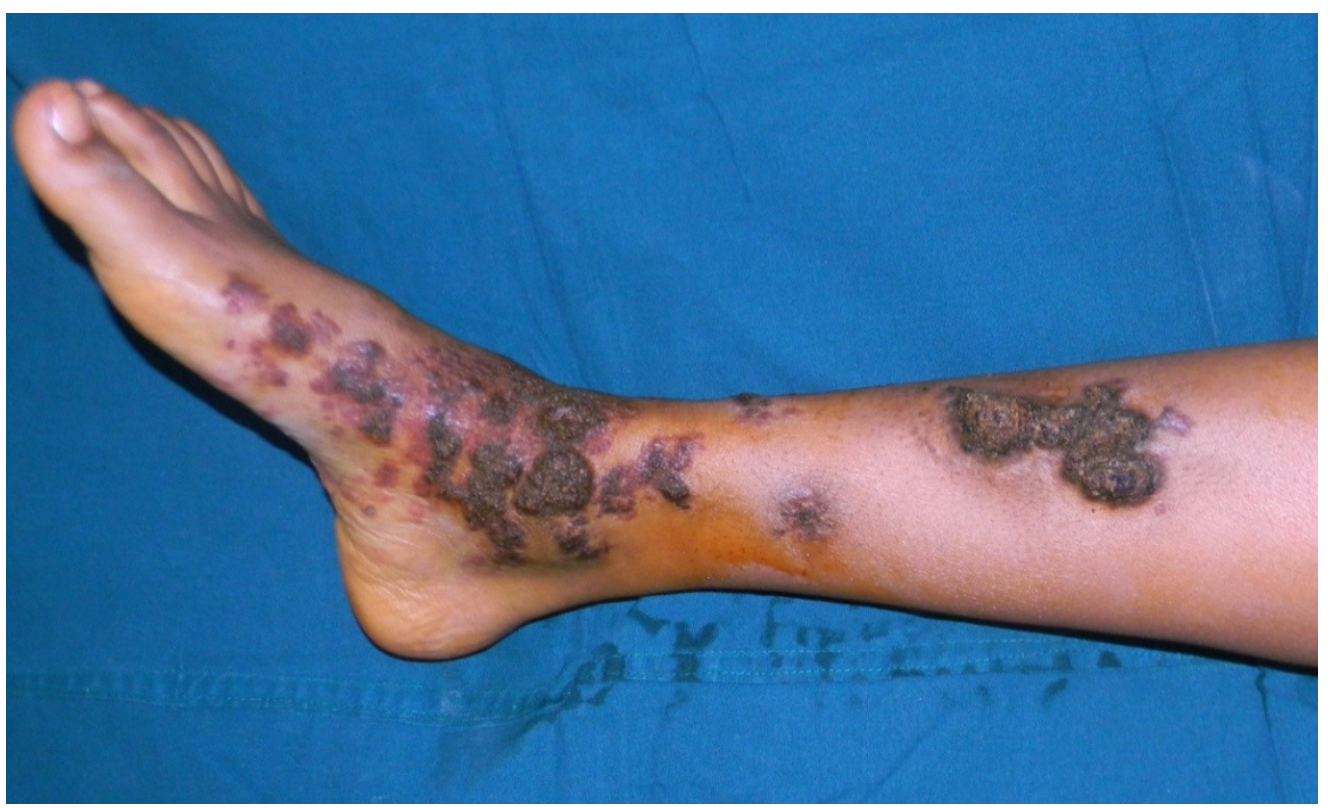

Figure 1 : Rt leg showing verrucous plaques, the upper one measuring more than $10 \mathrm{~cm}$ 


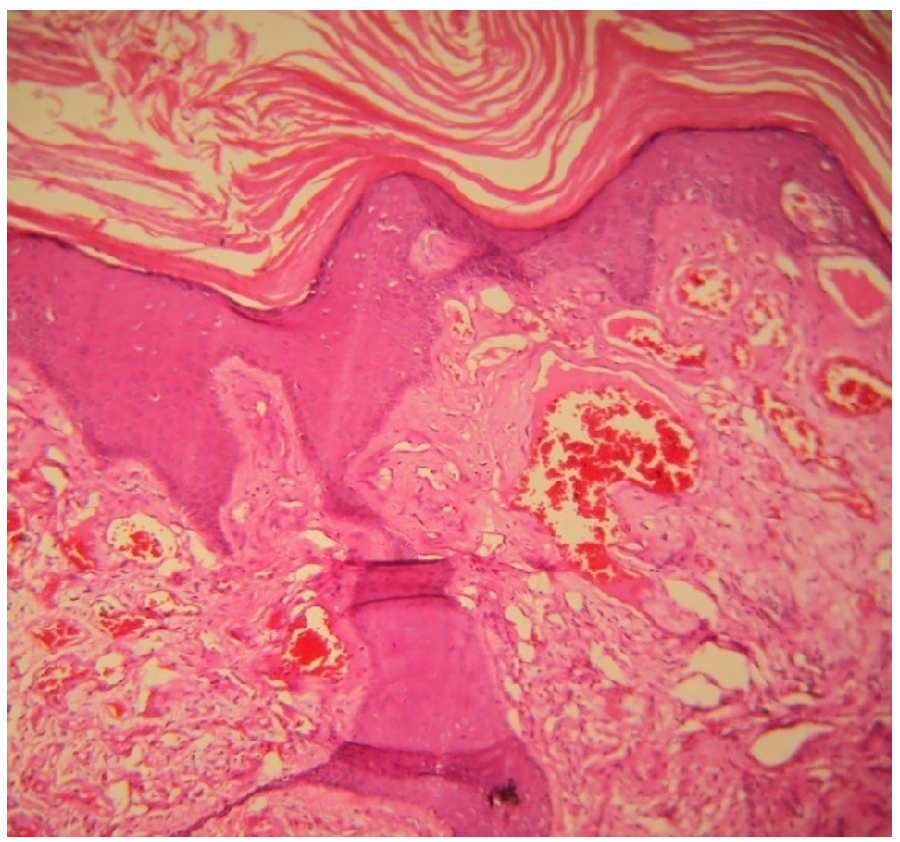

Figure 2: Low power view showing hyperkeratosis, acanthosis with ectatic vascular channels in the dermis (X10)

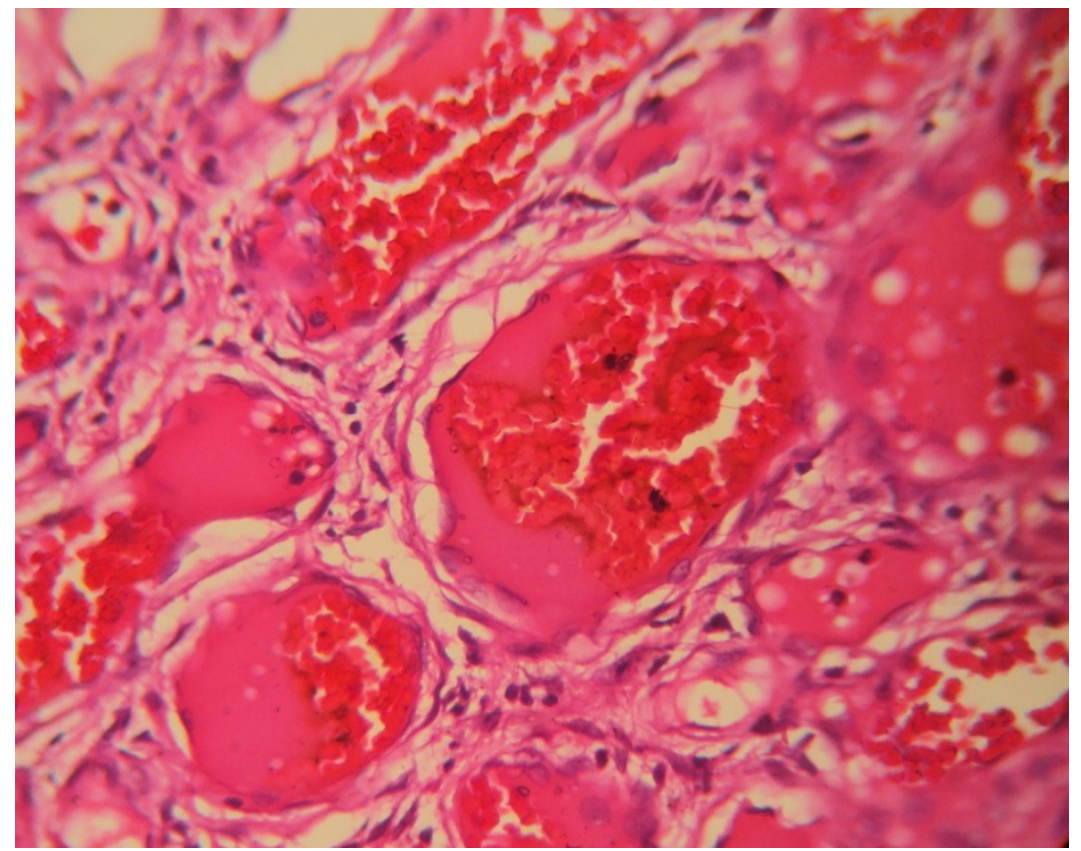

Figure 3: High power view showing ectatic vascular channels filled with red blood cells (X40) 


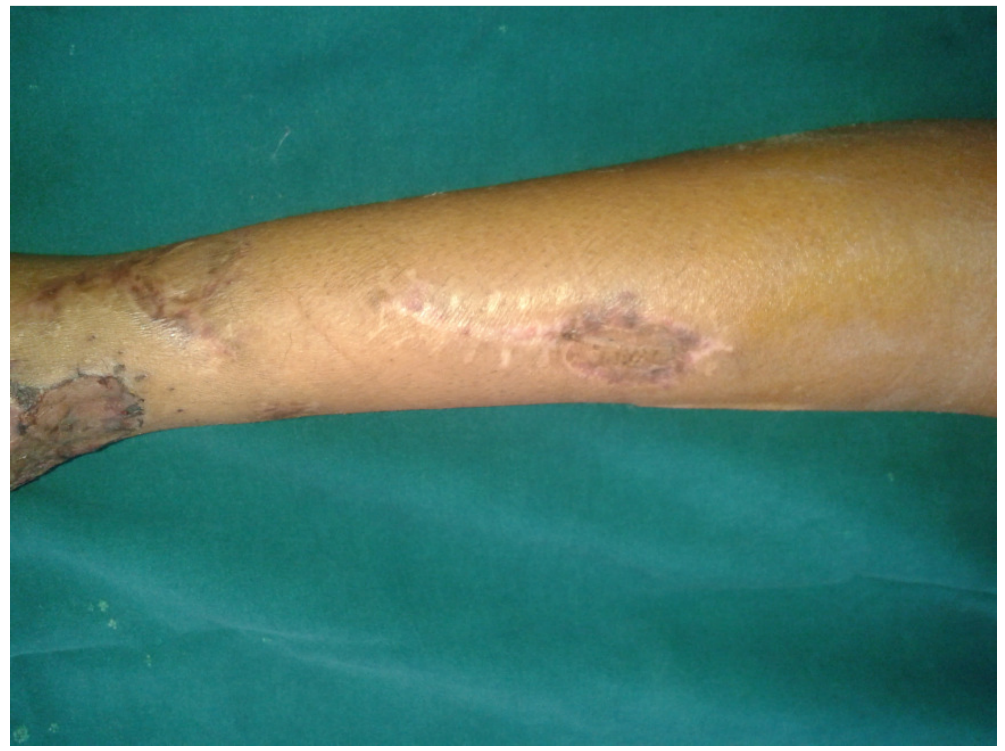

Figure 4: Four weeks post excision and grafting

\section{Discussion}

Verrucous hemangioma is a rare vascular malformation that presents either at birth or in childhood as bluish-red soft papules, plaques, and nodules over legs, which become verrucous later in life, or following trauma. Lesions may measure up to $8 \mathrm{~cm}$ in diameter. [1] In our case one plaque was measuring more than $10 \mathrm{~cm}$ in diameter. Halter coined the term verrucous hemangioma in 1937, but Imperial and Helwig described it in detail. [2] The involvement is usually unilateral, but a solitary case report of bilateral involvement has been reported.[3] Linear or serpiginous forms are rare with a few published reports.[4,5] The characteristichistopathological findings are the presence of ectatic vessels with an overlying hyperkeratotic and acanthotic epidermis. Because of the paucity of reports of linear verrucous hemangioma, it is not certain whether the distribution corresponds to the lines of Blaschko. Nevertheless, linear forms reflect genetic mosaicism, and it is appropriate to consider it as verrucous haemangioma with linear expression, rather than linear verrucous haemangioma [6]. The clinical differential diagnosis includes angiokeratoma, angioma serpiginosum, lymphangioama and pigmented tumours.[7] Recurrent bleeding and infection along with increase in size of the lesions following trauma are the usual complications.[8] This condition is usually asymptomatic, but the cosmetic appearance makes them feel embarrassed and seek treatment. Since our case was a female patient about to get married, we planned for complete excision and grafting. As though, there are many modalities of treatment for this condition like, cautery, lasers, cryotherapy which result in recurrence; surgical excision is the treatment of choice due to its deep extension. $[6,7]$

\section{Conclusion}

This case is being highlighted for its unusual giant, linear presentation and successful treatment with excision and grafting.

\section{Reference}

1. Moss C, Shahidullah H [2010]. Naevi and other developmental defects. In: Rook's text book of dermatology. Eds: Burns T, Breathnach S, Cox N, Griffiths C, $8^{\text {th }}$ edn, Wiley-Blackwell 18.1-18.107 
2. Imperial R, Helwig EB [1967]. Verrucous hemangioma: a clinicopathologic study of 21 cases. Arch Dermatol 96:247-253

3. Cruces MJ, De La Torre C [1995]. multiple eruptive verrucous hemangiomas: a variant of multiple hemangiomatosis. Dermatologica 171:106-111

4. Hayashi H, Shimizu T, Nakamura $H$, Shimizu H [2004]. Linear verrucous haemangioma on the abdomen Acta Derm Venereol 84:79-80
5. Klein JA, Barr RA [1985]. Verrucous hemangioma. Paediatr Dermatol 2:191-193

6. Wentscher U, Happle R [2000]. Linear verrucous hemangioma JAAD 42:516-519

7. Kaliyadan F, Dharmarathnam, AD, Jayasree MG, Sreekanth G [2009]. Linear verrucous hemangioma DOJ 15(5):15

8. Jain VK, Aggrawal K, Jain S [2008]. Linear verrucous hemangioma on the leg. IJDVL74:656-658 